Research Article

\title{
Role of N-Terminal Pro B-Type Natriuretic Peptide (NT-proBNP) for Diagnosing Underlying Cardiac and Extra-cardiac Diseases in Patients presenting with Acute Breathlessness in the Emergency Department
}

\author{
Nalini Bala Pandey', Dina] Shah ${ }^{2}$, Parneesh Arora ${ }^{3}$, AKMathur ${ }^{4}$ \\ ${ }^{1}$ Consultant Obstetrics and Gynaecology, Department of Obstetrics and Gynaecology, Lok Nayak Hospital, Delhi, India. \\ 2Director and Head of the Department, Department of Emergency Medicine, Fortis Hospital, Noida, Uttar Pradesh, India. \\ ${ }^{3}$ Additional Director, Department of Cardiology, Fortis Hospital, Noida, Uttar Pradesh, India. \\ ${ }^{4}$ Ex Scientist F, National Institute of Medical Statistics-Indian Council of Medical Research (ICMR), Delhi, India. \\ DOI: https://doi.org/10.24321/2349.7181.202113
}

\section{I $\quad \mathbf{N} \quad \mathbf{F} \quad \mathbf{O}$}

Corresponding Author:

Nalini Bala Pandey, Department of Obstetrics and Gynaecology, Lok Nayak Hospital, Delhi, India.

E-mail Id:

drnalinibala1981@gmail.com

Orcid Id:

https://orcid.org/0000-0003-0026-9563

How to cite this article:

Pandey NB, Shah DJ, Arora P, Mathur AK. Role of $\mathrm{N}$-Terminal Pro B-Type Natriuretic Peptide (NTproBNP) for Diagnosing Underlying Cardiac and Extra-cardiac Diseases in Patients presenting with Acute Breathlessness in the Emergency Department. J Adv Res Med. 2021;8(4):1-11.

Date of Submission: 2021-10-14

Date of Acceptance: 2021-12-09

\section{$\begin{array}{llllllll}\mathbf{A} & \mathbf{B} & \mathbf{S} & \mathbf{T} & \mathbf{R} & \mathbf{A} & \mathbf{C} & \mathbf{T}\end{array}$}

Background: Utility of NT-proBNP in patients presenting with acute breathlessness in the Emergency Department (ED) is high.

Aim and Objectives: To evaluate the role of NT-proBNP for early diagnosis of underlying cardiac and extra-cardiac diseases (renal, sepsis and respiratory failure) for patients presenting with acute breathlessness in the ED. The primary objective was correlation of NT-proBNP for diagnosing underlying diseases and the secondary objective was to establish its cutoff value to diagnose underlying diagnosis.

Methods: A prospective observational study was conducted on 241 patients with acute breathlessness in ED. They were categorised into two groups based on NT-proBNP values: Group 1 (high) and Group 2 (normal) as per their age-related pre-determined cut-offs. Correlation in terms of validity of NT-proBNP against underlying diagnosis and its diagnostic values were assessed. To estimate the cut-off value of NT-proBNP for underlying diseases, Receiver Operating Characteristics (ROC) curve was plotted.

Results: For underlying cardiac diseases, the cutoff value of NT-proBNP in ROC curve was $931.5 \mathrm{pg} / \mathrm{ml}$ (Sensitivity: $92.6 \%$, Specificity: $68.0 \%$, AUCs: $0.85, p<0.001$ ) and for renal diseases, the cutoff value of NT-proBNP was 2280 pg/ml (Sensitivity: 92.2\%, Specificity: 76.1\%, AUCs: 0.94, p<0.001).

Conclusion: This study established the role of NT-proBNP in indicating cardiac and renal involvement in patients presenting with acute breathlessness in the ED. In addition, normal NT-proBNP values rules out underlying cardiac and renal involvement. Also, higher NT-proBNP levels are indicative of multi-system involvement.

Keywords: Breathlessness, N-terminal pro-B-type Natriuretic Peptide, Heart Failure, Renal Failure, Sepsis 


\section{Introduction}

Acute breathlessness or shortness of breath is a common complaint among patients who come to the emergency department (ED). ${ }^{1}$ It can be triggered by a range of different illnesses and has multiple differential diagnoses based on the underlying diseases. ${ }^{2,3}$ Proper diagnosis can allow them to do accurate and prompt interventions for better outcomes and prognoses. ${ }^{4}$ Biomarkers have become an integral part of medicine, aiding in the diagnosis and treatment of numerous conditions. Biomarkers including B-type natriuretic peptide (BNP) and NT-proBNP have become important diagnostic tools for assessing patients of acute breathlessness. ${ }^{5}$ Both these biomarkers are helpful in the diagnosis and management of patients with heart failure. ${ }^{6}$ Clinicians need to expand their knowledge regarding the interpretation of elevated levels of natriuretic peptides and their potential clinical applications. ${ }^{7}$ The literature ${ }^{7-18}$ usually focuses on the role of NT-proBNP in heart failure settings, but only a few articles describe its role in extracardiac conditions, especially its cut-off values in renal diseases. ${ }^{19-20}$ In addition, there is a dearth of Indian studies on the role of NT-proBNP as a diagnostic and prognostic indicator in patients of acute breathlessness presenting in the ED in different clinical conditions.

\section{Study Objectives}

To evaluate the role of NT-proBNP for early diagnosis of underlying cardiac and extracardiac diseases (renal, sepsis, and respiratory failure) in patients presenting with acute breathlessness coming to the ED.

\section{Primary Objectives}

To assess the correlation of NT-proBNP with the underlying disease by comparing the NT-proBNP outcome against the underlying diagnosis made by the physician based on clinical diagnosis and laboratory (gold standard) test for these diseases. The underlying diseases and their standard tests were:

- Respiratory disease - Chest X-ray

- Cardiovascular disease - Echo-cardiogram

- Renal disease - Serum creatinine

- Septic marker - Pro-calcitonin

\section{Secondary Objective}

To establish the cut off value of NT pro-BNP to diagnose underlying diseases after plotting the Receiver Operating Characteristics (ROC) curve.

\section{Materials and Methods}

\section{Study Design}

The study was a prospective observational study, conducted at a single centre at Fortis Hospital, Noida, Uttar Pradesh, India for a period of one year, including all patients between 25 and 65 years of age with complaints of acute breathlessness triage code- $1^{21}$ coming to ED. Exclusion criteria included patients who had trauma, were on dialysis, were pregnant, or had cancer. Institutional ethical committee approval was taken and written informed consent was obtained before enrolment from all patients.

\section{Data Collection}

After enrolment, clinical characteristics of each patient were recorded including demographics, symptoms and signs, medical history, diagnostic tests done in ED such as echocardiographs, chest X-ray, and standard blood tests. $3 \mathrm{ml}$ of additional blood sample was taken for NTProBNP measurement. Study cases was categorised into two groups: Group-1 included patients with NT-proBNP clinically significant (high) values and Group-2 included the patients with NT-proBNP clinically not significant (normal) values, according to age-related pre-determined cut-offs ${ }^{8}$ ( $450 \mathrm{pg} / \mathrm{mL}$ for $<50$ years, $900 \mathrm{pg} / \mathrm{mL}$ for $50-75$ years, and $1800 \mathrm{pg} / \mathrm{mL}$ for $>75$ years).

\section{NT-Pro BNP Measurement}

For each trial, $3 \mathrm{ml}$ blood was collected into EDTA tubes. In ED, point of care testing of NT-proBNP was done using a standard commercially available assay - Triage Assay, Alere NT-proBNP test, and Bio-site Triple meter Pro. ${ }^{10}$

\section{Statistical Analysis}

The study was designed to include 264 patients to ensure a sample size of 238 patients assuming $10 \%$ attrition. Continuous data were presented as mean and standard deviation (SD) whereas categorical data were expressed in terms of frequencies and percentages. Descriptive statistics were calculated and differences in the mean of two independent groups, Group-1 (patients with clinically high NT-proBNP values) and Group-2 (patients with clinically normal NT-proBNP values) were compared by applying independent unpaired t-test while equality of variance was checked by Levene's test. Categorical data were expressed in frequencies in the two groups and were compared using chi-square test. A two-sided $p$-level of $<0.05$ was considered statistically significant.

An association between the diagnostic test (gold standard) and bio-marker values was looked for. Validity of the NTproBNP against the diagnostic test (gold standard) was assessed by sensitivity and specificity and its diagnostic value was assessed by positive predictive values, negative predictive values and likelihood ratio (LR). The degree of agreement between the bio-marker test and the diagnostic test (gold standard) was measured by applying the kappa index of agreement. To estimate the cutoff value of NT pro-BNP for underlying diseases. Receiver Operating Characteristics (ROC) curve was performed. Area Under Curve (AUC) was calculated and its level of significance was 
also estimated. Box Plot was also made for the symmetry of data.

\section{Result}

In one year, 436 patients came to the emergency department with complaints of acute breathlessness. After applying inclusion and exclusion criteria, 241 patients were taken up for the study as shown in Figure 1.

\section{Patient Demography}

Study cases were categorised into two groups on the basis of cut-off values of NT-proBNP (age-related). Clinically high NT-proBNP values were seen in 170 (71\%) patients and they were labelled as Group-1 whereas 71 (29\%) patients were having clinically normal NT-proBNP values and were labelled as Group-2.

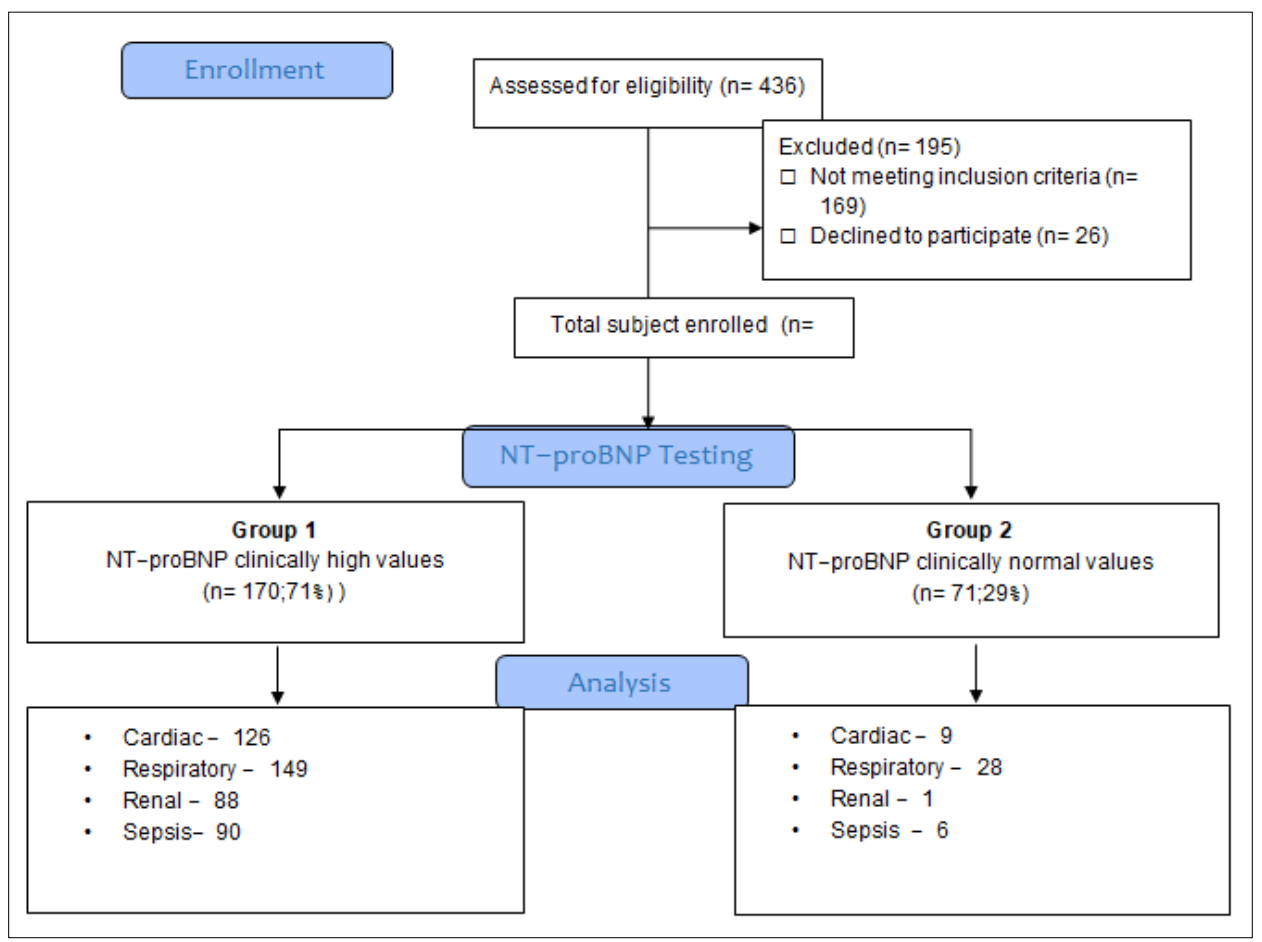

Figure I.CONSORT Flow Diagram for the Study

Table I.Baseline Characteristics of 24 I patients

\begin{tabular}{|c|c|c|c|c|c|c|}
\hline & & Group-1 $(n=170)$ & Group-2 $(n=71)$ & $p$-value & OR & $\begin{array}{c}\mathrm{Cl} \\
\text { (Min-Max) }\end{array}$ \\
\hline \multirow{2}{*}{$\begin{array}{l}\text { Gender, } \mathrm{n} \\
(\%)\end{array}$} & Male $(n=143)$ & $107(62.9)$ & $36(50.7)$ & 0.180 & & \\
\hline & Female $(n=98)$ & $63(37.1)$ & $35(49.3)$ & & & \\
\hline \multirow{2}{*}{ Age, $n(\%)$} & $<50$ yrs old & $36(21.2)$ & $21(29.5)$ & 0.162 & 1.6 & $0.8-2.9$ \\
\hline & $\geq 50$ yrs old & $134(78.8)$ & $50(70.5)$ & & & \\
\hline \multirow{5}{*}{$\begin{array}{c}\text { Clinical } \\
\text { parameters, } \\
\text { Mean } \pm \text { SD }\end{array}$} & Respiratory rate (Rate/min) & $32.2 \pm 6.80$ & $31.2 \pm 5.90$ & 0.230 & & \\
\hline & Heart rate (Rate/min) & $108.5 \pm 27.0$ & $103.0 \pm 24.0$ & 0.172 & & \\
\hline & Systolic BP (mmHg) & $134.9 \pm 27.0$ & $125.0 \pm 34.0$ & 0.058 & & \\
\hline & Diastolic BP (mmHg) & $80.1 \pm 15.30$ & $76.5 \pm 16.30$ & 0.122 & & \\
\hline & $\begin{array}{c}\text { Clinical assessment of sign of } \\
\text { failure, } n(\%)\end{array}$ & $157(92.2)$ & $47(66.2)$ & 0.001 & & \\
\hline \multirow{4}{*}{$\begin{array}{l}\text { Medical } \\
\text { history, } \\
\mathrm{n}(\%)\end{array}$} & Previous cardiac disease & $87(51.2)$ & $12(16.9)$ & 0.001 & 5.2 & $2.6-10.3$ \\
\hline & Diabetes $(n=112)$ & $88(51.8)$ & $24(33.8)$ & 0.010 & 2.1 & $1.2-3.7$ \\
\hline & Hypertension $(n=138)$ & $98(57.6)$ & $40(56.3)$ & 0.279 & 1.4 & $0.7-2.6$ \\
\hline & Deranged lipid profile $(n=29)$ & $26(15.3)$ & $3(4.2)$ & 0.016 & 4.1 & $1.2-13.9$ \\
\hline
\end{tabular}


The baseline characteristics of the patients among these groups are shown in Table 1.

There was no significant difference between gender and age distribution in both the groups, however, the majority of the patients in both the groups were of age 50 and above. There was no statistically significant difference in terms of respiratory rate, heart rate, systolic and diastolic BP in both groups. Clinical assessment of signs of heart failure (pulmonary crepitation and lower extremity oedema) was done by the emergency physician in ED and statistically significant.

The magnitudes of association of high NT-proBNP values with past medical history as shown in Table 1 . The chance of high NT-proBNP values in previous heart disease was 5 times, history of diabetes was 2.1 times, history of hypertension was 1.4 times, and deranged lipid profile was 4.1 times higher as compared to those patients who had no history of these medical diseases respectively. The information collected on smoking habits and consumption of alcohol is under-reported thus it could not be analysed.

The correlation of NT-proBNP with the underlying disease was done by comparing the NT-proBNP outcome against the underlying diagnosis made by the physician based on clinical diagnosis and laboratory (gold standard) test for confirmation of underlying diseases i.e. chest X-ray for respiratory disease, echo-cardiogram for cardiac disease, serum creatinine for renal disease, and procalcitonin for septic marker (Tables 2 and 3).

There was a statistically significant difference in both the groups in terms of underlying diseases (cardiac, respiratory, sepsis and renal) with the maximum in terms of underlying renal diseases and the gold standard investigation. It can also predict the severity of underlying heart failure, renal diseases, and sepsis as shown in Table 3. Both the tests including NT-proBNP and Echo findings have a substantial agreement as per Cohen Kappa as indicated in Table 3.

All the four diseases showed good sensitivity for NT-proBNP with a maximum sensitivity of $98.9 \%$ to underlying renal diseases and showed fair specificity i.e. maximum with underlying respiratory diseases (68.25\%). NT-proBNP has a good positive and negative predictive value i.e. underlying respiratory diseases (88.2\%) for positive predictive values and underlying renal diseases (98.5\%) for negative predictive values. Patients with high NT-proBNP have an increased likelihood of having underlying cardiac (LR+ $=2.34)$ and respiratory (LR+ $=2.65)$ diseases. NT-proBNP values within normal limits decrease the likelihood ratio of having a renal disease (LR- $=0.02$ ) as indicated in Table 4.

Table 2.Distribution of Diseases based on their Gold Standard Test

\begin{tabular}{|c|c|}
\hline Total Patients Investigated & Diseases Present, $\mathbf{n}$ (\%) \\
\hline Cardiac $(\mathrm{n}=238)$ & $135(56.7)$ \\
\hline Renal disease $(\mathrm{n}=227)$ & $89(39.6)$ \\
\hline Respiratory disease $(\mathrm{n}=240)$ & $177(73.8)$ \\
\hline Sepsis $(\mathrm{n}=222)$ & $96(43.2)$ \\
\hline
\end{tabular}

Table 3.Distribution of Diseases based on their Gold Standard Test

\begin{tabular}{|c|c|c|c|c|c|c|c|}
\hline Diseases Present & Abnormal Results & $\begin{array}{c}\text { Group-1 } \\
\text { n (\%) }\end{array}$ & $\begin{array}{c}\text { Group-2 } \\
\mathrm{n}(\%)\end{array}$ & $p$-value & OR & $\mathrm{Cl}$ & Kappa \\
\hline \multirow{3}{*}{$\begin{array}{c}\text { Cardiac }(n=135) \\
\text { (Echo findings) } \\
\text { EF (\%) }\end{array}$} & Mild (EF = 40-54) & $48(28.7)$ & $5(7.0)$ & \multirow{3}{*}{0.0001} & \multirow{3}{*}{21.2} & \multirow{3}{*}{$9.7-46.4$} & 0.601 \\
\hline & Moderate $(E F=30-39)$ & $67(40.1)$ & $4(5.5)$ & & & & \\
\hline & Severe $(\mathrm{EF}<35)$ & $11(6.6)$ & $0(0.0)$ & & & & \\
\hline \multirow{2}{*}{$\begin{array}{c}\text { Renal disease }(n=89) \\
\text { (Creatinine values) }\end{array}$} & $1.3-3.0$ & $60(37.7)$ & $1(1.5)$ & \multirow{2}{*}{0.0001} & \multirow{2}{*}{84.0} & \multirow{2}{*}{ 11.4-619.9 } & \multirow{2}{*}{0.504} \\
\hline & $>3.0$ & $28(17.6)$ & $0(0.0)$ & & & & \\
\hline \multirow{6}{*}{$\begin{array}{l}\text { Respiratory diseases } \\
\qquad(\mathrm{n}=177) \\
\text { X-ray findings }\end{array}$} & Pulmonary oedema & $41(24.3)$ & $2(2.8)$ & \multirow{6}{*}{0.0001} & \multirow{6}{*}{11.5} & \multirow{6}{*}{$5.8-22.6$} & 0.412 \\
\hline & LRTI & $78(46.2)$ & $21(29.6)$ & & & & \\
\hline & Pleural effusion & $17(10.1)$ & $1(1.4)$ & & & & \\
\hline & ARDS & $7(4.1)$ & $2(2.8)$ & & & & \\
\hline & ILD & $5(2.9)$ & $2(2.8)$ & & & & \\
\hline & Pneumothorax & $1(0.6)$ & $0(0.0)$ & & & & \\
\hline \multirow{2}{*}{$\begin{array}{l}\text { Sepsis }(n=96) \\
\text { S-pro calcitonin }\end{array}$} & (0.15 to 2.0$)$ & $40(25.5)$ & $5(7.7)$ & \multirow{2}{*}{0.0001} & \multirow{2}{*}{13.2} & \multirow{2}{*}{$5.4-32.5$} & 0.377 \\
\hline & $>2.0$ & $50(31.8)$ & $1(1.5)$ & & & & \\
\hline
\end{tabular}


Table 4.Sensitivity, Specificity, Positive and Negative Predictive Values, and Positive and Negative Likelihood Ratio of NT-proBNP with Underlying Disease

\begin{tabular}{|c|c|c|c|c|c|c|c|c|c|}
\hline \multirow{2}{*}{$\begin{array}{l}\text { Statistical } \\
\text { tools }\end{array}$} & & \multicolumn{2}{|c|}{ Cardiac } & \multicolumn{2}{|c|}{ Respiratory } & \multicolumn{2}{|c|}{ Renal } & \multicolumn{2}{|c|}{ Sepsis } \\
\hline & & Value (\%) & $95 \% \mathrm{Cl}$ & Value (\%) & $95 \% \mathrm{Cl}$ & Value (\%) & $95 \% \mathrm{Cl}$ & Value (\%) & $95 \% \mathrm{Cl}$ \\
\hline \multirow{2}{*}{ Validity } & Sensitivity & 93.30 & $\begin{array}{c}87.72- \\
96.91 \\
\end{array}$ & 84.20 & $\begin{array}{l}77.95- \\
89.22 \\
\end{array}$ & 98.90 & $\begin{array}{c}93.96- \\
99.97 \\
\end{array}$ & 93.75 & $\begin{array}{c}86.89- \\
97.67 \\
\end{array}$ \\
\hline & Specificity & 60.20 & $\begin{array}{l}50.08 \\
-69.71\end{array}$ & 68.20 & $\begin{array}{c}55.31- \\
79.42\end{array}$ & 47.50 & $\begin{array}{c}38.95- \\
56.12\end{array}$ & 46.83 & $\begin{array}{c}37.88- \\
55.92\end{array}$ \\
\hline \multirow{2}{*}{$\begin{array}{l}\text { Diagnostic } \\
\text { values }\end{array}$} & PPV & 75.45 & $\begin{array}{l}70.70- \\
79.65\end{array}$ & 88.17 & $\begin{array}{c}83.76- \\
91.50\end{array}$ & 54.94 & $\begin{array}{c}50.96- \\
58.85\end{array}$ & 57.32 & $\begin{array}{c}53.08- \\
61.47\end{array}$ \\
\hline & NPV & 87.32 & $\begin{array}{c}78.24- \\
92.96\end{array}$ & 60.56 & $\begin{array}{c}51.24- \\
69.17\end{array}$ & 98.51 & $\begin{array}{c}90.32- \\
99.79\end{array}$ & 90.77 & $\begin{array}{c}81.59- \\
95.62\end{array}$ \\
\hline \multirow{2}{*}{$\begin{array}{l}\text { Diagnostic } \\
\text { accuracy }\end{array}$} & LR+ & 2.34 & $\begin{array}{c}1.84- \\
2.99 \\
\end{array}$ & 2.65 & $\begin{array}{c}1.84- \\
3.83\end{array}$ & 1.88 & $\begin{array}{c}1.61- \\
2.21\end{array}$ & 1.76 & $\begin{array}{c}2.82- \\
133.17\end{array}$ \\
\hline & LR- & 0.11 & $\begin{array}{c}0.06- \\
0.21\end{array}$ & 0.23 & $\begin{array}{c}0.16- \\
0.34\end{array}$ & 0.02 & $\begin{array}{c}0.01- \\
0.17\end{array}$ & 0.13 & $0.06-0.30$ \\
\hline
\end{tabular}

Table 5.Result of ROC Curve of NT-proBNP Cutoff Values for Underlying Diseases

\begin{tabular}{|c|c|c|c|c|c|c|}
\hline $\begin{array}{c}\text { Diseases } \\
\text { Name }\end{array}$ & $\begin{array}{c}\text { NT-proBNP Cutoff } \\
\text { Values (pg/mI) }\end{array}$ & Sensitivity (\%) & Specificity (\%) & Area under Curve & p-value & Cl (95\%) \\
\hline Cardiac & 931.5 & 92.6 & 68.0 & 0.85 & 0.0001 & 0.800 \\
\hline Renal & 2280.0 & 92.2 & 76.1 & 0.94 & 0.0001 & 0.910 \\
\hline Sepsis & 908.0 & 90.1 & 49.2 & 0.81 & 0.0001 & 0.751 \\
\hline Respiratory & 822.0 & 82.0 & 71.5 & 0.87 & 0.0001 & 0.823 \\
\hline
\end{tabular}

To establish the cutoff value of NT pro-BNP to diagnose underlying diseases, Receiver Operating Characteristics (ROC) curve was plotted as shown in Figures 2 and 3. The cut-off values of NT-proBNP for underlying cardiac disease, renal disease, respiratory disease, and sepsis shown in Table 5 and are found to be statistically significant.

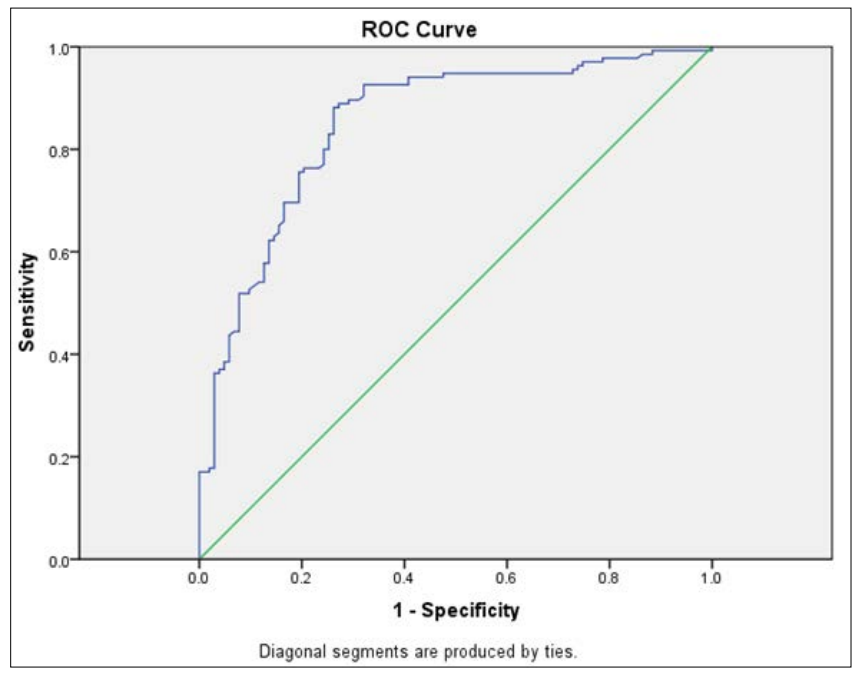

Figure 2.ROC Curve of NTpro-BNP for underlying Cardiac Diseases

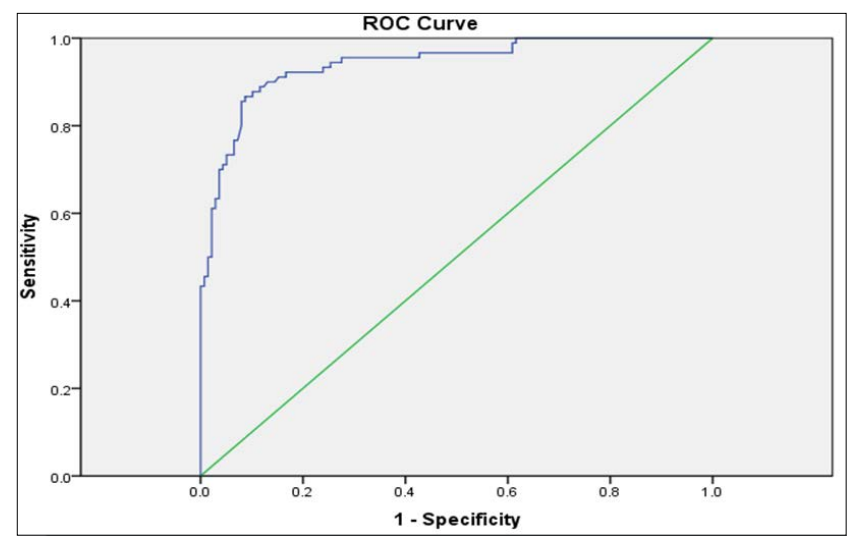

Figure 3.ROC curve of NTpro-BNP for underlying renal diseases

Result of ROC curve of NT-proBNP and clinical signs of diseases (failure) with underlying cardiac diseases shown in Figure 4. Area under curve for NT pro-BNP was $81.4 \%$ and for clinical signs of diseases (failure) was $67.1 \%$. When NT pro-BNP combined with clinical signs of diseases (failure), the Area under curve increased to $86.2 \%$. NT pro-BNP alone was superior to clinical signs of disease (failure). It was significantly better when results of NT pro-BNP combined with clinical signs of diseases (failure) for estimating acute heart failure. 


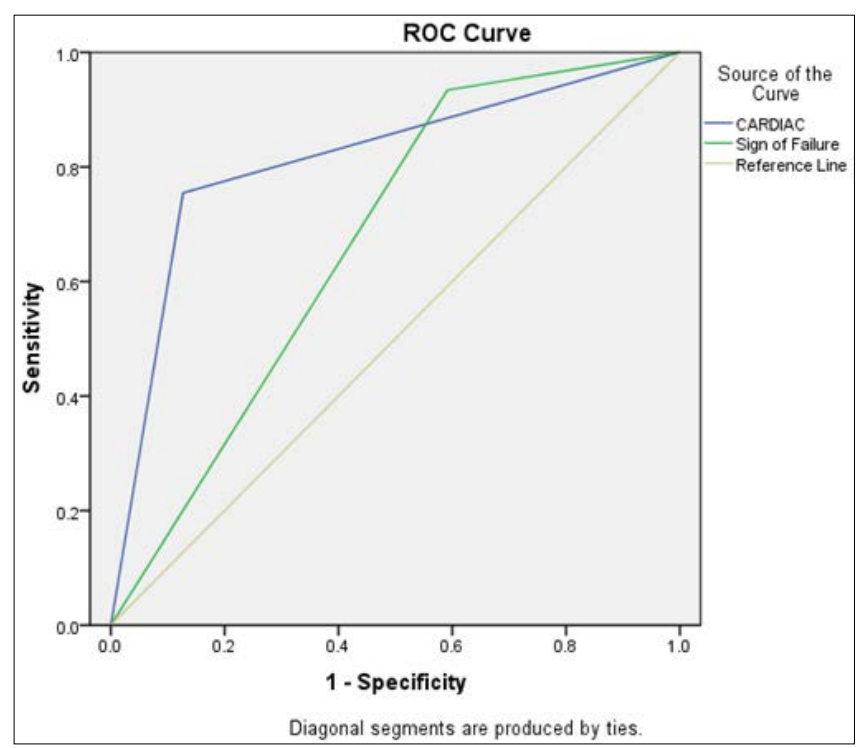

Figure 4.ROC Curve of NTpro-BNP, Clinical Sign of Failure, and a Combination of Both for underlying Cardiac Disease

After applying Kruskal Wall's test, median value of NTproBNP in the patients with no disease group was 557 $\mathrm{pg} / \mathrm{ml}$ and in patients having all four disease was 3470 $\mathrm{pg} / \mathrm{ml}$ and difference was highly statistically significant ( $p$-value $<0.001)$. Thus, we can say that increasing NTproBNP values is associated with multi-organ involvement and comorbidities (Table 6).

\section{Discussion}

Acute breathlessness is a common complaint among patients who came to the ED. ${ }^{1}$ Acute breathlessness indicates the presentation of a wide range of diseases ranging from a benign ailment to a fatal disease. It is, therefore, very important to diagnose the cause of acute breathlessness correctly and treat it appropriately. Proper diagnosis can allow them to do an accurate and prompt intervention for their better outcome and prognosis. ${ }^{4}$

Biomarkers have become an integral part of medicine, aiding in the diagnosis and treatment of numerous conditions. The natriuretic peptides (NPs), B-type natriuretic peptide (BNP) and NT-proBNP are commonly used in the evaluation of heart failure, but their role extends beyond diagnosis and includes risk stratification and prognosis for the patients who present acutely with dyspnoea. ${ }^{5}$

In the study, prevalence of breathlessness was more among males as compared to females; this was in concordance with the study done by James L Januzzi et al. ${ }^{8}$ and A BeyesGenis et al. ${ }^{15}$

An appropriate sample size $(n=241)$ had given us an opportunity to further examine the relationship between gender and NT-proBNP levels. In this study, NT-proBNP results were comparable in both males and females and gender stratification added no further diagnostic value for evaluating subjects in concordance with the International Collaborative of NT-proBNP (ICON) study ${ }^{18}$ in which pooled analysis of the studies of James $L$ Januzzi et al., ${ }^{8}$ A BeyisGenis et al., ${ }^{15}$ Maisel AS et al., ${ }^{11}$ and John Lainchbury et al. ${ }^{18}$ were done.

In this study, the mean (SD) age of patients was $55.8 \pm 9.6$ ranging from 25 to 65 years and the majority of patients were in the age group of 50-65 years of age as shown in Table 7. James $L$ Januzzi et al. ${ }^{8}$ reported median age of $72.8 \pm 13.6(27-94)$ years in their study. The difference in median age might be due to the selection criteria as there was no age limit in their study and our study is limited to the age group of 25 to 65 years of age in order to avoid age-related morbidity and mortality.

The prevalence of breathing difficulty in our study was $76.5 \%$ in the age group of 50 and above years which is in concordance with the study done by James L Januzzi et al. ${ }^{8}$ where it was $70.2 \%$. In this study, clinical assessment of signs of failure (pulmonary crepitation and lower extremity oedema ${ }^{8}$ ) came out to be $65 \%$ in CHF patients and $19.5 \%$ in non-CHF patients which was in concordance with the study done by James $L$ Januzzi et al. ${ }^{8}$ who reported it as $48 \%$ in CHF patient and $14 \%$ in non-CHF patients. This difference was statistically significant $(p<0.0001)$ in both studies.

Table 6.Comparison of Medians of NT-proBNP in No Diseases and All Four Diseases Groups

\begin{tabular}{|c|c|c|c|}
\hline NT-proBNP $(\mathbf{p g} / \mathbf{m l})$ & No Disease $(\mathbf{n}=\mathbf{1 0 3})$ & All 4 Diseases $(\mathbf{n}=\mathbf{5 3})$ & p-value \\
\hline 25th percentile & 182 & 1436 & $<0.001^{\#}$ \\
\hline 50th percentile (Median) & 557 & 3470 & 10550 \\
\hline
\end{tabular}

\#-Kruskal Wall's test for comparing the median of the groups of no diseases and all four diseases.

Table 7.Comparison of Age-wise Distribution in Our Study with another Study

\begin{tabular}{|c|c|c|}
\hline Age (years) & This Study $\mathbf{n}(\%)$ & James L Januzzi et al. $^{\mathbf{8}} \mathbf{n}(\%)$ \\
\hline 50 and above & $184(76.5)$ & $455(75.2)$ \\
\hline Less than 50 & $57(23.7)$ & $144(24.2)$ \\
\hline Total & $241(100)$ & $599(100)$ \\
\hline
\end{tabular}


Disease categorisation was done to correlate it with biomarker NT-proBNP values and to understand the underlying disease in breathing difficulty patients. In this study, as expected, there were a variety of diagnoses as aetiology of breathing difficulty with acute CHF (57.7\%) being the most prevalent which was in concordance with the study done by James L Januzzi et al. ${ }^{8}$ who reported CHF in $34.8 \%$ of patients with acute breathlessness. Cases of pneumonia in this study were as high as $41.3 \%$. Only $9.9 \%$ of patients had an acute coronary syndrome similar to $5.7 \%$ in the study of James $L$ Januzzi et al. ${ }^{8}$. Pulmonary embolism accounts for only $2.9 \%$ of patients in our study similar to that in the study by James L Januzzi et al. (Table 8). The diagnosis of underlying disease was overlapping with other cases, which attributed to spontaneous pneumothorax, sepsis, volume overload, anxiety, ascites, cardiac arrhythmia, pericarditis or other unknown aetiology.

\section{Association of NT-proBNP with underlying Cardiac Diseases}

In this study, pre-determined cutoff values of NT-proBNP (the optimal cut-offs based on age for the diagnosis of acute heart failure (HF) among acute breathlessness patients were estimated to be $450 \mathrm{pg} / \mathrm{ml}$ for $<50$ years and $900 \mathrm{pg} / \mathrm{ml}$ for $50-65$ years $^{8}$ ) in CHF patients shows $93.3 \%$ sensitivity, 60.2\% specificity, 72.4\% PPV, and $87.3 \%$ NPV as shown in Figure 5. This is in concordance with the International Collaborative of NT-proBNP (ICON) study, ${ }^{18}$ which formed an optimal strategy to identify acute CHF according to these age-related cut-offs. This confirmatory strategy was associated with a sensitivity of $90 \%$, a specificity of $84 \%$, and a positive predictive value of $88 \%^{5,8}$ (Figure 6 ).

In this study for underlying cardiac diseases, the cutoff value of NT-proBNP obtained was $931.5 \mathrm{pg} / \mathrm{ml}$ at $92.6 \%$ sensitivity, $68 \%$ specificity with $85.1 \%$ area under curve and it is statistically significant (Table 9). This is in concordance with James $L$ Januzzi et al. ${ }^{8}$ who also showed similar results.

In this study, the median of NT-proBNP values among patients with no CHF was $557 \mathrm{pg} / \mathrm{ml}$, that among patients with mild CHF was $3470 \mathrm{pg} / \mathrm{ml}$. and with moderate to severe CHF was $4054 \mathrm{pg} / \mathrm{ml}$ as depicted in Figure 6 and Table 10. This is in concordance with the study by James $L$ Januzzi et al. ${ }^{8}$ in which median of NT-proBNP value in no CHF patients was $131 \mathrm{pg} / \mathrm{ml}$ and in CHF patients was 4054 $\mathrm{pg} / \mathrm{ml}$. Thus increasing NT-proBNP values correlate with the severity of $\mathrm{CHF}(\mathrm{p}<0.001)$.

Table 8.Comparison of Diseases Distribution in Our Study with another Study

\begin{tabular}{|c|c|c|c|c|c|c|}
\hline & Acute CHF & COPD/ Asthma & Pneumonia & ACS & PE & Others \\
\hline This Study & $57.7 \%$ & $25 \%$ & $41.3 \%$ & $5.2 \%$ & $2.9 \%$ & ---- \\
\hline James L Januzzi et al. ${ }^{8}$ & $34.8 \%$ & $14.5 \%$ & $11.0 \%$ & $9.9 \%$ & $3.1 \%$ & ----- \\
\hline
\end{tabular}

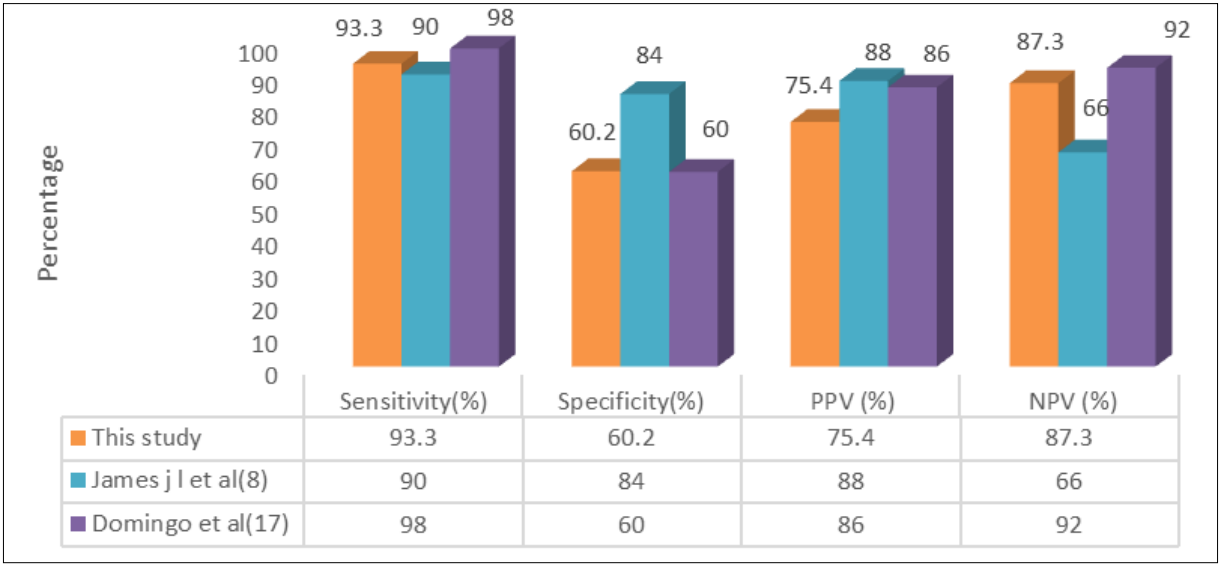

Figure 5.Comparison of Validity and Diagnostic Values of NT-proBNP in Cardiac Disease among Different Studies

Table 9.Comparison of Result of ROC Curve for NT-proBNP Cutoff Values for Underlying Cardiac Disease in Our Study with Another Study

\begin{tabular}{|c|c|c|c|c|c|}
\hline & $\begin{array}{c}\text { NT-proBNP } \\
\text { Cutoff Values }\end{array}$ & $\begin{array}{c}\text { Sensitivity } \\
\%\end{array}$ & $\begin{array}{c}\text { Specificity } \\
\%\end{array}$ & $\begin{array}{c}\text { Area under } \\
\text { Curve }\end{array}$ & p-value \\
\hline James L Januzzi et al. $^{8}$ & 900 & 90 & 85 & 0.94 & 0.0001 \\
\hline This study & 931.5 & 92.6 & 68 & 0.85 & 0.0001 \\
\hline
\end{tabular}




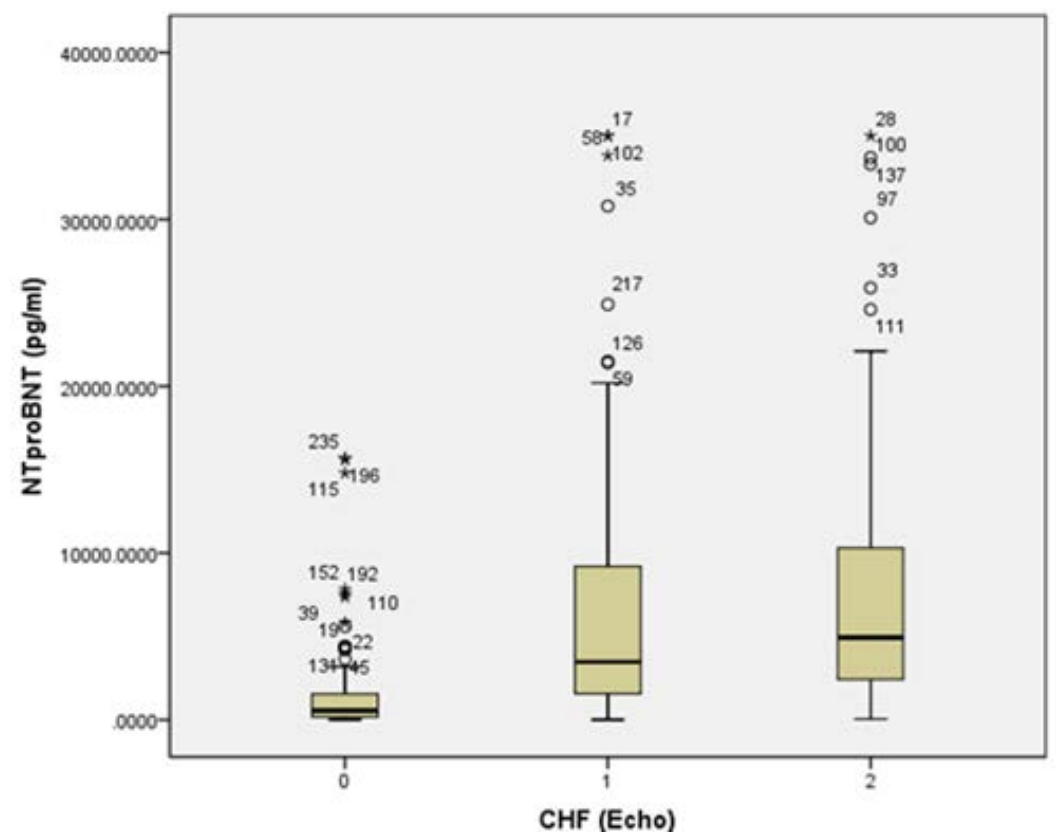

(0: No heart failure; 1 : Mild heart failure; 2 : Moderate to Severe heart failure)

Figure 6.Median of NT-proBNP Levels among Patients with Acute CHF $(n=135)$ and without CHF (n = 103); $\mathrm{p}<0.001$. Whiskers graph, 5th and 95th percentile

Table 10.Comparison of Median of NT-proBNP in Levels among Patients who had Acute CHF (n = 135) and who did not in Our Study with Another Study

\begin{tabular}{|c|c|c|c|c|}
\hline Diagnostic Category & \multicolumn{2}{|c|}{ This Study } & \multicolumn{2}{|c|}{ James L Januzzi et al. ${ }^{8}$} \\
\hline *Echo finding & $\begin{array}{c}\text { Median } \\
\text { NT-proBNP (pg/ml) }\end{array}$ & $\begin{array}{c}25 \text { th- } 75 \text { th } \\
\text { percentile }(\mathrm{pg} / \mathrm{ml})\end{array}$ & $\begin{array}{c}\text { Median } \\
\text { NT-proBNP (pg/ml) }\end{array}$ & $\begin{array}{c}\text { 25th-75th } \\
\text { percentile }(\mathrm{pg} / \mathrm{ml})\end{array}$ \\
\hline No CHF & 557 & $182-1650$ & 131 & $46-433$ \\
\hline Mild CHF & 3470 & $1436-10550$ & \multirow{2}{*}{4054} & \multirow{2}{*}{$1675-10029$} \\
\hline Moderate to Severe CHF & 4940 & 2427-10425 & & \\
\hline
\end{tabular}

Note: The statistical difference in no CHF and CHF group in each study is highly significant $(p<0.001)$.

*According to ACC classification ${ }^{22}$

\section{Extracardiac Diseases}

\section{Sepsis}

In our study, NT-proBNP was positive in $93.8 \%$ of patients with an underlying diagnosis of sepsis formed by correlating physician's diagnosis and laboratory findings of PCT (procalcitonin) in patients with acute breathlessness coming to the Emergency Department. In sepsis, NT-proBNP values were elevated and statistically significant with $p<0.001$. This is in concordance with the studies done by Alain Rudiger ${ }^{2}$ and Brueckmann et al. ${ }^{23}$

We concluded that NT-proBNP seems to be an objective and useful approach for diagnosing and establishing sepsis severity in concordance with Mina Hur et al. ${ }^{24}$ who showed similar results.

Table I I.Comparison of the Present Study with Previous Studies for NT-proBNP in Sepsis

\begin{tabular}{|c|c|c|c|c|}
\hline NT-proBNP & Our Study & Fei Wang et al. ${ }^{25}$ & Mokart D et al. $^{\mathbf{2 6}}$ & Brueckmann et al. $^{\mathbf{2 3}}$ \\
\hline Sensitivity & $93.8 \%$ & $79.0 \%$ & $86.0 \%$ & $50.0 \%$ \\
\hline Specificity & $46.8 \%$ & $60.0 \%$ & $77.0 \%$ & $90.2 \%$ \\
\hline LR+ & 1.76 & 2.27 & - & - \\
\hline LR- & 0.13 & 0.32 & - & - \\
\hline PPV & $57.3 \%$ & - & $79.0 \%$ & $66.7 \%$ \\
\hline NPV & $90.8 \%$ & - & $85.0 \%$ & $82.2 \%$ \\
\hline
\end{tabular}


In our study, NT-proBNP showed good sensitivity, LR+ and NPV for underlying sepsis, which was in concordance with the studies done by Khoury J Fei Wang et al. ${ }^{25}$ and Mokart D et al. ${ }^{26}$ (Table 11).

\section{Renal}

In our study, NT-proBNP was positive in $98.8 \%$ of the patients with the underlying diagnosis of renal disease formed by correlating clinical diagnosis and lab values of serum creatinine. NT-proBNP showed excellent sensitivity (98.9\%), specificity (47.5\%), PPV (54.9\%), negative predictive value (98.5\%) and Odds ratio (84) for underlying renal disease in acute breathlessness patients in our study. NT pro-BNP values within normal limits highly decrease the likelihood ratio of having a renal disease (LR- $=0.02$ ).

In this study, the NT-proBNP value obtained was $2280 \mathrm{pg} /$ $\mathrm{ml}$ at $92.2 \%$ sensitivity and $76.1 \%$ specificity with $94.1 \%$ area under curve, with statistically significant $p$ values. NT-proBNP values were influenced by renal function in concordance with the study done by Srisawasdi P. ${ }^{19}$ Thus, one can rule out renal involvement if NT-proBNP value is within normal limits.

\section{Respiratory}

In our study, NT-proBNP was positive in $84.2 \%$ of the patients with an underlying diagnosis of respiratory disease formed by correlating clinical diagnosis and chest X-ray. NT-proBNP showed sensitivity (84.2\%), specificity (68.2\%), PPV (88.17\%), negative predictive value (60.56\%) and Odds ratio (11.5) for underlying respiratory disease in acute breathlessness patients in our study. High NT proBNP values show an increased likelihood ratio of having a respiratory disease $(\mathrm{LR}+=2.65)$. High NT-proBNP value can indicate the severity of illness of patients with acute respiratory failure which was in concordance with a study done by Patrick Ray et al. ${ }^{27}$ who concluded that for assessing the severity of illness of patients with acute respiratory failure, physicians should focus more on easily available criteria associated with higher mortality; hypercapnia, elevated levels of BNP or NT-proBNP, and clinical signs of acute ventilator failure. ${ }^{27}$

NT-proBNP had a significant role in both cardiac and extracardiac conditions in patients presenting with acute breathlessness.

\section{Limitations}

This study was conducted at a single centre in India, thus the generalisation of the finding outside this geographic region may be limited.

\section{Recommendation}

- $\quad$ Patients with breathing difficulty should undergo NT-
proBNP test on arrival in ED for early diagnosis of underlying disease.

- NT-proBNP pre-determined cutoffs can be extrapolated to our study population.

- $\quad$ Future research is warranted to clarify the assay standardisation, the optimal cut-off value of NT-proBNP in conjunction with the non-cardiac condition.

\section{Conclusion}

This study established the role of NT-proBNP in indicating cardiac and renal involvement but could not predict underlying respiratory involvement and sepsis in patients presenting with acute breathlessness in the ED. In addition, normal NT-proBNP values rules out underlying cardiac and renal involvement. Also, higher NT-proBNP levels are indicative of multi-system involvement.

\section{Acknowledgement}

We wish to acknowledge the assistance of the doctors, nursing and paramedical staff of the emergency department and intensive care unit of the Fortis Hospital, Noida, patients who have participated in the study, my family and the scientific staff of ICMR for the unfailing support and courtesy.

\section{Source of Funding: None Conflict of Interest: None \\ References}

1. Tintinalli JE, Stapczynski JS, Ma OJ, Cline DM, Meckler GD, Yealy DM, editors. Tintinalli's emergency medicine: a comprehensive study guide. 8th ed. New York: McGraw-Hill Education; 2016 Mar 22.

2. Rudiger A, Gasser S, Fischler M, Hornemann T, von Eckardstein A, Maggiorini M. Comparable increase of B-type natriuretic peptide and amino-terminal pro-B-type natriuretic peptide levels in patients with severe sepsis, septic shock, and acute heart failure. Crit Care Med. 2006 Aug;34(8):2140-4. [PubMed] [Google Scholar]

3. Wang AY, Lai KN. Use of cardiac biomarkers in end-stage renal disease. J Am Soc Nephrol. 2008 Sep;19(9):164352. [PubMed] [Google Scholar]

4. Faggiano P, Valle R, Aspromonte N, D’Aloia A, Di Tano G, Barro S, Giovinazzo P, Milani L, Lorusso R, Dei Cas L. How often we need to measure brain natriuretic peptide (BNP) blood levels in patients admitted to the hospital for acute severe heart failure?: Role of serial measurements to improve short-term prognostic stratification. Int J Cardiol. 2010 Apr 1;140(1):88-94. [PubMed] [Google Scholar]

5. Wettersten N, Maisel AS. Biomarkers for heart failure: an update for practitioners of internal medicine. Am 
J Med. 2016 Jun 1;129(6):560-7. [PubMed] [Google Scholar]

6. Mangla A. Brain-Type Natriuretic Peptide (BNP): Reference range, Interpretation. emedicine.medscape. com update 2021 https://emedicine.medscape.com/ article/2087425-overview

7. Palazzuoli A, Gallotta M, Quatrini I, Nuti R. Natriuretic peptides (BNP and NT-proBNP): measurement and relevance in heart failure. Vasc Health Risk Manag. 2010;6:411. [PubMed] [Google Scholar]

8. Januzzi Jr JL, Camargo CA, Anwaruddin S, Baggish AL, Chen AA, Krauser DG, Tung R, Cameron R, Nagurney JT, Chae CU, Lloyd-Jones DM, Brown DF, Foran-Melanson S, Sluss PM, Lee-Lewandrowski E, Lewandrowski KB. The N-terminal pro-BNP investigation of dyspnea in the emergency department (PRIDE) study. Am J Cardiol. 2005 Apr 15;95(8):948-54. [PubMed] [Google Scholar]

9. Sarzani R, Spannella F, Giulietti F, Fedecostante M, Giordano P, Gattafoni P, Espinosa E, Busco F, Piccinini $G$, Dessì-Fulgheri P. NT-proBNP and its correlation with in-hospital mortality in the very elderly without an admission diagnosis of heart failure. Plos One. 2016 Apr 14;11(4):e0153759. [PubMed] [Google Scholar]

10. Khezri BS, Carlsson L, Larsson A. Evaluation of the Alere NT-proBNP Test for Point of Care Testing. J Clin Lab Anal. 2016 Jul;30(4):290-2. [PubMed] [Google Scholar]

11. Daniels LB, Maisel AS. Natriuretic peptides. J Am Coll Cardiol. 2007 Dec 18;50(25):2357-68. [PubMed] [Google Scholar]

12. Tsai SH, Lin YY, Chu SJ, Hsu CW, Cheng SM. Interpretation and use of natriuretic peptides in non-congestive heart failure settings. Yonsei Med J. 2010 Mar 1;51(2):15163. [PubMed] [Google Scholar]

13. Hall C. Essential biochemistry and physiology of (NT-pro) BNP. Eur J Heart Fail. 2004 Mar;6(3):257-60. [PubMed] [Google Scholar]

14. Bay M, Kirk V, Parner J, Hassager C, Nielsen H, Krogsgaard K, Trawinski J, Boesgaard S, Aldershvile J. NT-proBNP: a new diagnostic screening tool to differentiate between patients with normal and reduced left ventricular systolic function. Heart. 2003 Feb 1;89(2):150-4. [PubMed] [Google Scholar]

15. Bayes-Genis A, Santalo-Bel M, Zapico-Muniz E, Lopez L, Cotes C, Bellido J, Leta R, Casan P, Ordonez-Llanos J. $\mathrm{N}$-terminal probrain natriuretic peptide (NT-proBNP) in the emergency diagnosis and in-hospital monitoring of patients with dyspnoea and ventricular dysfunction. Eur J Heart Fail. 2004 Mar;6(3):301-8. [PubMed] [Google Scholar]

16. Bettencourt P, Azevedo A, Pimenta J, Frioes F, Ferreira $\mathrm{S}$, Ferreira A. N-terminal-pro-brain natriuretic peptide predicts outcome after hospital discharge in heart failure patients. Circulation. 2004 Oct 12;110(15):216874. [PubMed] [Google Scholar]

17. Figal DA, Sanchez MC, Velasco JA, Pina TC, Gimeno LM, Rodriguez RG, Abizanda JA, Hernandez PM, Chavarri MV. [Usefulness of NTproBNP in the emergency management of patients with severe dyspnea and an uncertain heart failure diagnosis]. Rev Esp Cardiol. 2005 Oct;58(10):1155-61. Spanish. [PubMed] [Google Scholar]

18. Januzzi JL, van Kimmenade R, Lainchbury J, BayesGenis A, Ordonez-Llanos J, Santalo-Bel M, Pinto YM, Richards M. NT-proBNP testing for diagnosis and shortterm prognosis in acute destabilized heart failure: an international pooled analysis of 1256 patients: the International Collaborative of NT-proBNP Study. Eur Heart J. 2006 Feb 1;27(3):330-7. [PubMed] [Google Scholar]

19. Srisawasdi $P$, Vanavanan $S$, Charoenpanichkit C, Kroll $\mathrm{MH}$. The effect of renal dysfunction on BNP, NT-proBNP, and their ratio. American journal of clinical pathology. 2010 Jan 1;133(1):14-23.[PubMed] [Google Scholar]

20. Anwaruddin S, Lloyd-Jones DM, Baggish A, Chen A, Krauser D, Tung R, Chae C, Januzzi Jr JL. Renal function, congestive heart failure, and amino-terminal pro-brain natriuretic peptide measurement: results from the ProBNP Investigation of Dyspnea in the Emergency Department (PRIDE) Study. J Am Coll Cardiol. 2006 Jan 3;47(1):91-7. [PubMed] [Google Scholar]

21. Aacharya RP, Gastmans C, Denier Y. Emergency department triage: an ethical analysis. BMC Emerg Med. 2011;11:16. [PubMed] [Google Scholar]

22. Heart failure- ACC clinical toolkit. Left Ventricular Ejection Fraction (LVEF). American College of Cardiology 2014. https://www.acc.org/ tools-and-practice-support/clinical-toolkits/ / media/1E4D8F9B69D14F55821BFE642FBFA221.ashx

23. Brueckmann $M$, Huhle $G$, Lang $S$, Haase KK, Bertsch $T$, Weiß C, Kaden JJ, Putensen C, Borggrefe M, Hoffmann $U$. Prognostic value of plasma N-terminal pro-brain natriuretic peptide in patients with severe sepsis. Circulation. 2005 Jul 26;112(4):527-34. [PubMed] [Google Scholar]

24. Hur M, Kim H, Lee S, Cristofano F, Magrini L, Marino R, Gori CS, Bongiovanni C, Zancla B, Cardelli P, Di Somma S. Diagnostic and prognostic utilities of multimarkers approach using procalcitonin, B-type natriuretic peptide, and neutrophil gelatinase-associated lipocalin in critically ill patients with suspected sepsis. BMC Infect Dis. 2014 Dec;14(1):224. [PubMed] [Google Scholar]

25. Wang F, Wu Y, Tang L, Zhu W, Chen F, Xu T, Bo L, Li J, Deng $X$. Brain natriuretic peptide for prediction of mortality in patients with sepsis: a systematic review 
and meta-analysis. Crit Care. 2012;16(3):R74. [PubMed] [Google Scholar]

26. Mokart D, Sannini A, Brun JP, Faucher M, Blaise D, Blache JL, Faucher $\mathrm{C}$. N-terminal pro-brain natriuretic peptide as an early prognostic factor in cancer patients developing septic shock. Crit Care. 2007 Apr;11(2):R37. [PubMed] [Google Scholar]

27. Ray $P$, Birolleau $S$, Lefort $Y$, Becquemin $M H$, Beigelman C, Isnard R, Teixeira A, Arthaud M, Riou B, Boddaert J. Acute respiratory failure in the elderly: etiology, emergency diagnosis and prognosis. Crit Care. 2006 Jun;10(3):R82. [PubMed] [Google Scholar] 